\title{
Technologie i opowiadanie o przeszłości a wyzwania animacji kultury
}

\author{
Technologies, historical storytelling, \\ and the challenges of cultural animation
}

\author{
||Joanna Zętar
IORCID: 0000-0002-0377-6272),
Łukasz Kowalski
Ośrodek „Brama Grodzka - Teatr NN” Lublin
}

\begin{abstract}
On March 12, 2020, the crisis staff with the Minister of Culture and National Heritage introduced a lockdown in Poland. For most cultural institutions, it was the beginning of activity in completely different conditions and a necessity to redefine the activities. For nearly three months, cultural institutions deprived of the possibility of normal stationary work. They had to face the challenge of operating on-line. It quickly turned out that retransmissions of events, recalling archival recordings and virtual walks are not solutions that can keep the audience's attention for a long time. The aim of the text is to examine the conditions and methods in which culture, and education, can and should be realized today. The article presents an example of activities carried out in Lublin by the "Grodzka Gate - NN Theater" Center, which since the late 1990s uses the Internet and new technologies in history and local cultural heritage. The authors of the article look for answers to the questions how cultural institutions are prepared to operate with the use of new technologies and how they implement the goals of humanities education.
\end{abstract}

Key words: animation of culture, education, new technology, Internet, history, cultural heritage, „Grodzka Gate - NN Theater” Center

Streszczenie: 12 marca 2020 roku sztab kryzysowy z udziałem ministra kultury i dziedzictwa narodowego wprowadził w Polsce lockdown. Dla większości instytucji był to początek aktywności w zupełnie innych warunkach i przymus redefinicji dotychczasowych działań. Przez blisko trzy miesiące instytucje kultury pozbawione możliwości normalnej, stacjonarnej pracy musiały się zmierzyć z wyzwaniem funkcjonowania on-line. Szybko okazało się, że retransmisje wydarzeń, przypominanie archiwalnych nagrań ze spotkań autorskich i wirtualne spacery nie są rozwiązaniem, które na długo jest w stanie utrzymać uwagę publiczności. W celem tekstu jest przyjrzenie się warunkom i metodom, w jakich kultura, a zarazem edukacja może i powinna być dziś realizowana. Na tle prowadzonych przez polskie instytucje kultury działań animacyjnych i edukowania w nowej formie przedstawiony został przykład działań prowadzonych w Lublinie, przez Ośrodek „Brama Grodzka - Teatr NN”, który od końca lat 90. wykorzystuje w swoich działaniach internet i nowe technologie do przekazywania wiedzy o historii i lokalnym dziedzictwie kulturowym. 
Autorzy w artykule szukają odpowiedzi na pytania czy instytucje kultury są przygotowane do działań z użyciem nowych technologii oraz jak realizują cele edukacji humanistycznej.

Słowa kluczowe: animacja kultury, edukacja, nowe technologie, Internet, historia, dziedzictwo kulturowe, Ośrodek „Brama Grodzka - Teatr NN”

(...) w niespokojnych i zaskakujących czasach, w których na naszych oczach zmienia się rzeczywistość: znikają znane drogowskazy i stałe punkty orientacyjne, ale też otwierają się inne perspektywy i możliwości. Potrzebne stają się nowe pomysły i idee ${ }^{1}$.

\section{\#zostań w domu}

12 marca 2020 roku sztab kryzysowy z udziałem ministra kultury i dziedzictwa narodowego zdecydował o czasowym zamknięciu instytucji kultury, filharmonii, oper, operetek, teatrów, muzeów, kin, domów kultury, bibliotek, galerii sztuki oraz szkół, uczelni wyższych i placówek szkolnictwa artystycznego. Dla większości instytucji był to moment nagłego hamowania, następnie zatrzymania się, dezorientacji, a w konsekwencji czas refleksji i namysłu wynikający z konieczności działania w zupełnie innych warunkach oraz zredefiniowania dotychczasowych działań. Przez blisko trzy miesiące - do końca maja 2020 roku - instytucje kultury pozbawione możliwości normalnej, stacjonarnej pracy musiały przede wszystkim zmierzyć się $\mathrm{z}$ wyzwaniem funkcjonowania online $\mathrm{w}$ nowych warunkach. Strony internetowe zawierające jedynie informacje o instytucji i wydarzeniach, które nie mogły się odbywać, przestały się sprawdzać. Dość szybko okazało się też, że retransmisje wydarzeń, przypominanie archiwalnych nagrań i wirtualne spacery nie są w stanie na długo utrzymać uwagi publiczności, która początkowo szukała w sieci rozrywki i odskoczni od komunikatów zakazujących kolejnych aktywności w ramach izolacji, ale z czasem zaczęła poszukiwać tego, co ją interesuje.

Jedną z instytucji, które szybko zareagowały na lockdown, było Muzeum POLIN. Na stronie internetowej Muzeum umieszczono zakładkę: „Muzeum POLIN w Twoim Domu”, gdzie zebrano propozycje do wykorzystania w sposób zdalny. Użytkownicy mogli wirtualnie zwiedzić wystawę stałą i wystawy czasowe, zapoznać się z relacjami z wydarzeń organizowanych przez Muzeum, zapisami dyskusji z cykli „Między religiami”, „Kłopoty z tożsamością” i „Czytelnia POLIN”. Kiedy muzeum nie prowadziło tradycyjnej działalności edukacyjnej, na stronie internetowej udostępniono bazę materiałów w formie plików PDF, filmów, quizów, lekcji online. Wśród nich

1 Z wypowiedzi Grzegorza Zygadły zapowiadającego inaugurację działalności Fundacji Olgi Tokarczuk. Za: Fundacja Olgi Tokarczuk już działa. 12 listopada ukaże się nowa ksiażka, https://www.onet.pl/informacje/onetwroclaw/inauguracja-fundacji-olgi-tokarczuk-i-zapowiedz-nowej-ksiazki/pn9gj4t,79cfc278 (dostęp: 23.10.2020). 
były także materiały pokonferencyjne oraz odsyłacz do Radia POLIN uruchomionego 15 kwietnia $2020 \mathrm{r}$. W programie internetowej stacji radiowej znalazły się m.in. relacje z wykładów, spotkań i debat, które organizowane były w muzeum, wywiady ze świadkami historii i muzyka. Radia POLIN słuchać można na platformie SLOTEX oraz za pomocą popularnych odtwarzaczy. Specjalne wydanie audycji Radia POLIN było wyemitowane w dniu 94. urodzin Mariana Turskiego.

Do sieci przeniesiono także tegoroczne obchody rocznicy wybuchu powstania w getcie warszawskim. Akcja społeczno-edukacyjna „Żonkile”, wykłady, spacer po wystawie głównej muzeum a także po Muranowie były transmitowane za pośrednictwem You Tube'a i Facebooka. O zainteresowaniu wydarzeniami świadczy liczba odsłon poszczególnych materiałów: spacer Beaty Chomątowskiej „Tu było getto” - 4536 wyświetleń, wykład Jacka Leociaka o doświadczeniach cywilnych podczas powstania w getcie warszawskim miał 1606, wyświetleń modlitwa Naczelnego Rabina Polski Michaela Schudricha - 1002 wyświetlenia.

Międzynarodowe Centrum Kultury w Krakowie w zapowiedzi jednej ze swoich propozycji na czas lockdownu napisało:

W ostatnich miesiącach zostaliśmy zmuszeni do porzucenia swoich zwyczajów, nawyków i rytuałów oraz dystansowania się. Nie musi to jednak oznaczać $\mathrm{w}$ naszym rozumieniu wyłącznie izolacji i samotnie przeżywanego znudzenia. Jak pisała Wisława Szymborska: »kto patrzy z góry, ten najłatwiej się myli«. Patrzenie $\mathrm{z}$ dystansu było od zawsze ważne $\mathrm{w}$ naszych działaniach, bo pozwalało na mówienie o kulturze i historii oraz poruszanie wielu, często niełatwych tematów².

Z tego myślenia wywodzi się projekt „Złap dystans - wirtualne spotkania w MCK", czyli osiem rozmów o Krakowie, Europie Środkowej, architekturze i sztuce przeprowadzonych m.in. z Krzysztofem Czyżewskim, Julią Fiedorczuk, Jackiem Purchlą i Filipem Springerem. Inna propozycja MCK to cykl „Europa od środka, czyli inspirująca podróż palcem po mapie”, czyli dwadzieścia pięć tekstów o miejscach rzeczywistych i wyobrażonych, artystach, budowlach, miastach i regionach. Inspiracją dla tematów podjętych w tekstach były wystawy prezentowane w Galerii MCK. Materiały z cyklu publikowane na stronie internetowej MCK były też udostępniane za pośrednictwem Facebooka. Międzynarodowe Centrum Kultury przygotowało także ofertę dla nauczycieli szkół podstawowych i średnich zatytułowaną „Użyj dziedzictwa! Lekcje o dziedzictwie kulturowym on-line”. Były to spotkania z edukatorami MCK skoncentrowane wokół zagadnień związanych z dziedzictwem materialnym i niematerialnym, wielokulturowością, społeczeństwem obywatelskim, a także praktyczną wiedzą o tym, jak mądrze korzystać z zasobów kultury w sieci. Ofertę edukacyjną uzupełniono materiałami z publikacji wydawanych przez centrum udostępnionymi szerszemu gronu odbiorców. Artykuły naukowe z zakresu dziedzictwa, publikacje

${ }^{2}$ Cyt. za: Cykl wirtualnych wydarzeń w MCK, https://mck.krakow.pl/aktualnosci/zlap-dystans-cykl-wirtualnych-wydarzen-w-mck (dostęp: 23.10.2020). 
pokonferencyjne, zbiory esejów i innych publikacji umieszczono na stronie internetowej w zakładce: „Z biblioteki MCK”. Bardzo ciekawym, choć słabo wyeksponowanym i opisanym na stronie głównej instytucji, jest jej kanał na You Tubie. Można na nim znaleźć filmy i relacje z wydarzeń, począwszy od materiałów związanych z wystawą „Pamięć. Rejestry i terytoria” zorganizowaną w 2014 roku, poprzez kolejne Fora Dziedzictwa Europejskiego, aż do warsztatów edukacyjnych. Największym zainteresowaniem internautów cieszą się materiały wideo: filmy z cyklu „Złap dystans” miały średnio 60 wyświetleń, materiały archiwalne do 200 wyświetleń.

Muzeum Sztuki Współczesnej MOCAK w Krakowie na czas lockdownu zaproponowało wirtualne zwiedzanie wystaw czasowych (niestety propozycja jest trudna do obsługi ze względu na użycie wtyczki Flash), ponadto udostępniono w formie plików PDF materiały edukacyjne „Twórcza Kolekcja”, a także numery archiwalne czasopisma „MOCAK Forum”. Dla osób szczegółowo zainteresowanych zasobami MOCAK-u ciekawą ofertą może okazać się prezentacja kolekcji muzealnej online uporządkowana według artystów i dzieł. Pod koniec kwietnia uruchomiono też projekt „MOCAK Sounds”. W serwisie Spotify można znaleźć następujące playlisty: „Bliżej natury" - playlista zawierająca muzykę filmową nawiązującą do świata przyrody; „MOCAK Café Sounds” - zestaw utworów przygotowany razem z MOCAK Café pozwalający doświadczyć atmosfery miejscowej kawiarni; „Art Sounds” - lista piosenek odnoszących się do sztuki; „MOCAK Home Office" - playlista z piosenkami słuchanymi przez pracowników muzeum w czasie pracy zdalnej. We współpracy z użytkownikami powstawała też lista „\#yourMOCAK”, przygotowana przez zwiedzających na podstawie ich skojarzeń z muzeum.

Nie tylko instytucje państwowe i samorządowe, ale także wiele organizacji pozarządowych przygotowało swoje oferty na czas lockdownu. Jedną z takich organizacji jest Fundacja Centrum Cyfrowe, której celem jest wspieranie otwartości i zaangażowania w świecie nowoczesnych technologii. Fundacja pracuje na rzecz zmiany społecznej i zwiększenia zaangażowania obywatelskiego, wykorzystując narzędzia cyfrowe i modele współpracy oparte na dzieleniu się zasobami i wiedzą. Już 18 marca Centrum Cyfrowe na swojej stronie uruchomiło zakładkę „\#zostan w domu \#zostan z kulturą" zawierającą informacje o ofercie kulturalnej, którą można wykorzystać do edukacji, rozrywki i działań twórczych. Ciekawą propozycją Fundacji jest akcja \#PoużywajSobie, w której Centrum zachęca do korzystania z zasobów muzeów, galerii i bibliotek - nie tylko polskich, lecz także z całego świata. Na stronie można m.in. znaleźć instrukcję, jak przeprowadzić warsztat z tworzenia kolaży, który można zaadaptować do warunków domowych. Centrum opublikowało też pod hasłem „Edukacja zdalna, życie w sieci" teksty i analizy na czas pandemii.

Zbiorcze informacje dotyczące oferty kulturalnej instytucji były publikowane w serwisach internetowych Ministerstwa Kultury i Dziedzictwa 
Narodowego, Narodowego Centrum Kultury, na portalu www.kulturadostepna.pl, a także na stronach internetowych urzędów miast. Większość z nich była opatrywana hasztagiem \#zostanwdomu albo \#kultura w kwarantannie.

\section{Wiedza i technologia}

Zaproponowany przegląd propozycji instytucji kultury rodzi pytanie o warunki i metody realizacji przez nie zadań. Czy instytucje te są przygotowane do działań animacyjnych i edukowania w nowej formie, w nowych uwarunkowaniach? Czy radzą sobie ze świadomym użyciem współczesnych technologii komunikacyjnych? Jak najlepiej realizować cele edukacji humanistycznej w ten właśnie sposób?

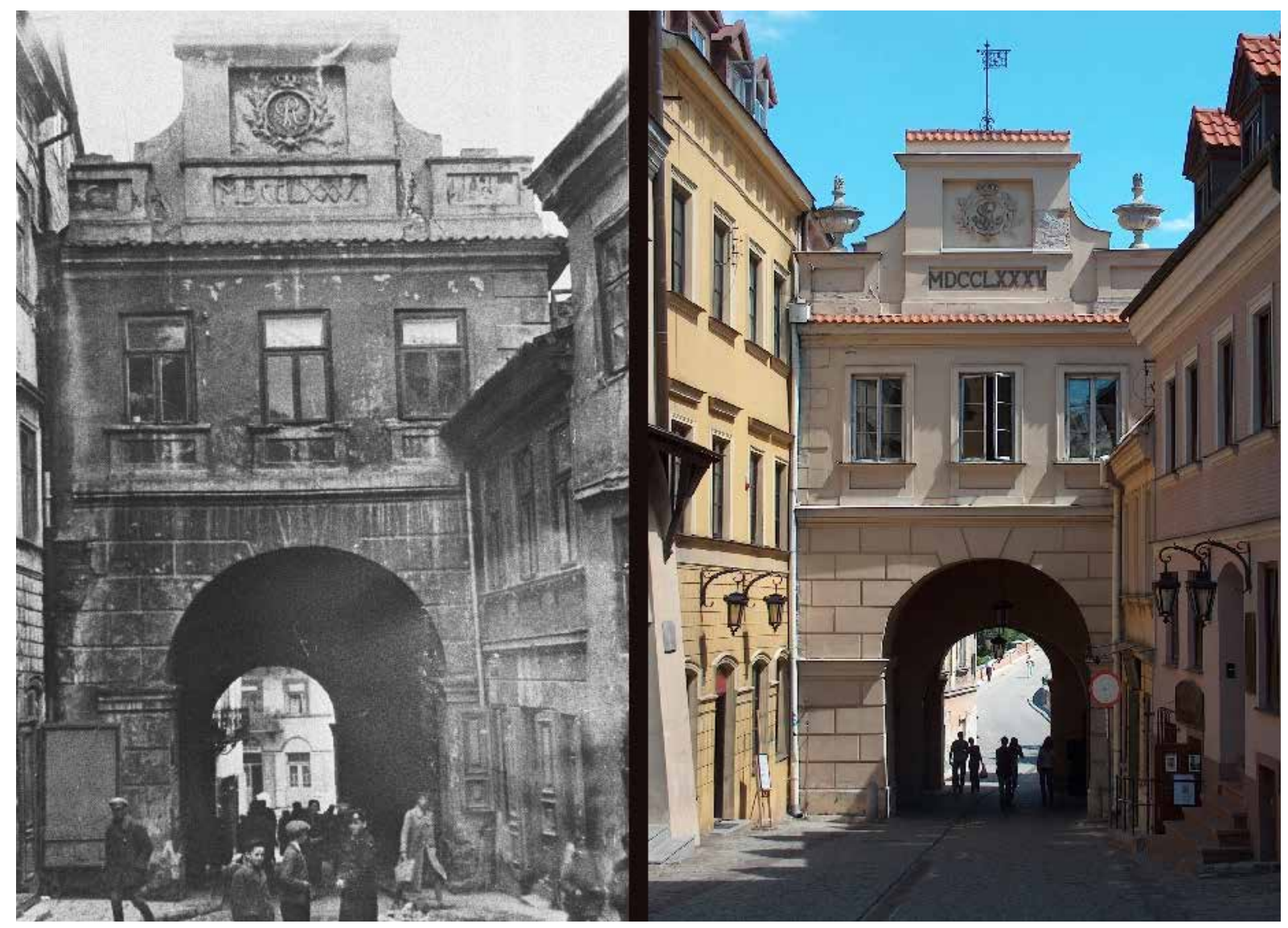

Ilustracja nr 1: Brama Grodzka w Lublinie w okresie przedwojennym i współcześnie, zdjęcia ze zbiorów Pracowni Ikonografii Ośrodka „Brama Grodzka - Teatr NN”

Przykładem instytucji, która poradziła sobie w tej sytuacji, jest Ośrodek „Brama Grodzka - Teatr NN”, który od przełomu XX i XXI stulecia wykorzystuje w swoich działaniach Internet i rozwijające się technologie komunikacyjne przede wszystkim w celu przekazywania wiedzy o historii i lokalnym dziedzictwie kulturowym. Twórca i założyciel ośrodka - Tomasz Pietrasiewicz - w manifeście Wirtualnej Biblioteki Lublina i Regionu Lubelskiego zainaugurowanej w 2003 roku napisał: 
Tradycyjne metody opowiadania o przeszłości coraz bardziej zawodzą i nie są już atrakcyjne dla młodego pokolenia. Używając nowych technologii i wykorzystując możliwości, jakie ona niesie, ośrodek rozpoczyna budowanie jakościowo nowych form popularyzacji dziedzictwa kulturowego ${ }^{3}$.

Historia projektów internetowych ośrodka rozpoczęła się w 2001 roku, kiedy powstał pomysł przygotowania portalu „Lublin. Pamięć Miejsca” popularyzującego Lublin i dziedzictwo kulturowe miasta. Jego twórcy chcieli zaprezentować historię Lublina, wykorzystując możliwości, jakie dawało nowe medium - Internet. W ramach tego działania tworzone były bazy danych, pozwalające na gromadzenie i udostępnianie za pomocą Internetu dokumentów tekstowych, materiałów ikonograficznych oraz materiałów audio. W maju 2003 roku ośrodek wystąpił z inicjatywą stworzenia przez lubelskie biblioteki i archiwa „Wirtualnej Biblioteki Lublina i Regionu Lubelskiego". Była to jedna z pierwszych tego typu inicjatyw w Polsce. Punktem wyjścia miało być doświadczenie ośrodka związane z jego dotychczasowymi projektami internetowymi. Niestety, ta wspólna w zamyśle idea nie doczekała się wtedy realizacji i związku z tym ośrodek rozwijał projekt samodzielnie.

„Wirtualna Biblioteka Lublina i Regionu Lubelskiego” dawała możliwość zapoznania się z tekstami poświęconymi lokalnej historii, wspomnieniami świadków historii oraz miniwykładami specjalistów z różnych dziedzin. Można było też zobaczyć zdjęcia związane z konkretnym wydarzeniem lub z codziennym życiem. Z czasem „Wirtualna Biblioteka Lublina i Regionu Lubelskiego” została przekształcona w „Bibliotekę Multimedialną Teatru NN”, a wraz z nią powstał portal „Leksykon Lublin”, gdzie zgromadzono teksty dotyczące historii i dziedzictwa kulturowego Lublina i regionu lubelskiego wraz z materiałami źródłowymi gromadzonymi w repozytorium Biblioteki.

Kiedy w marcu 2020 roku ośrodek w związku z wybuchem pandemii Covid-19 musiał zawiesić działalność, wszystkie aktywności zostały przeniesione do Internetu. 3 maja 2020 roku dziennikarz lubelskiego oddziału „Gazety Wyborczej” Tomasz Kowalewicz w podsumowaniu artykułu, w którym analizował, jak instytucje kultury radzą sobie podczas lockdownu, napisał:

Wydaje się, że najlepiej w tym wyścigu radzi sobie ośrodek „Brama Grodzka - Teatr NN". Przeglądając jego zasoby, można odnieść wrażenie, że na taki scenariusz, z jakim zmagamy się obecnie, instytucja przygotowywana była od lat ${ }^{4}$.

Oferta ośrodka przedstawiała wybrane projekty, które w ostatnim czasie były realizowane przez tę instytucję. Jednym z najważniejszych są wirtualne i multimedialne opowieści o Lublinie tworzone przez Ośrodek „Brama Grodzka - Teatr NN”. To narracje o ludziach, miejscach i wydarzeniach związanych z historią i dziedzictwem Lublina, publikowane przede wszystkim za pośrednictwem serwisu Leksykon Lublin (http://teatrnn.pl/

${ }^{3}$ Cyt. za: Historia Ośrodka "Brama Grodzka - Teatr NN", http://teatrnn.pl/kalendarium/wydarzenia/historia-osrodka-brama-grodzka-teatr-nn (dostęp: 23.10.2020).

${ }^{4}$ T. Kowalewicz, Jak lubelska kultura radzi sobie w trybie online, „Gazeta Wyborcza. Lublin. Tygodnik", s. 4. 
leksykon), jak również inne serwisy ośrodka, które popularyzują wiedzę dotyczącą Lublina i Lubelszczyzny, na przykład przewodniki po mieście dostępne na stronie Przewodniki Teatru NN pod adresem: (http://teatrnn. pl/przewodniki-lublin), gdzie m.in. można zwiedzić Lublin śladami renesansu lubelskiego, przejść po miejscach ważnych dla lubelskiej społeczności żydowskiej albo zapoznać się z miejscami opisanymi w Poemacie o mieście Lublinie Józefa Czechowicza.

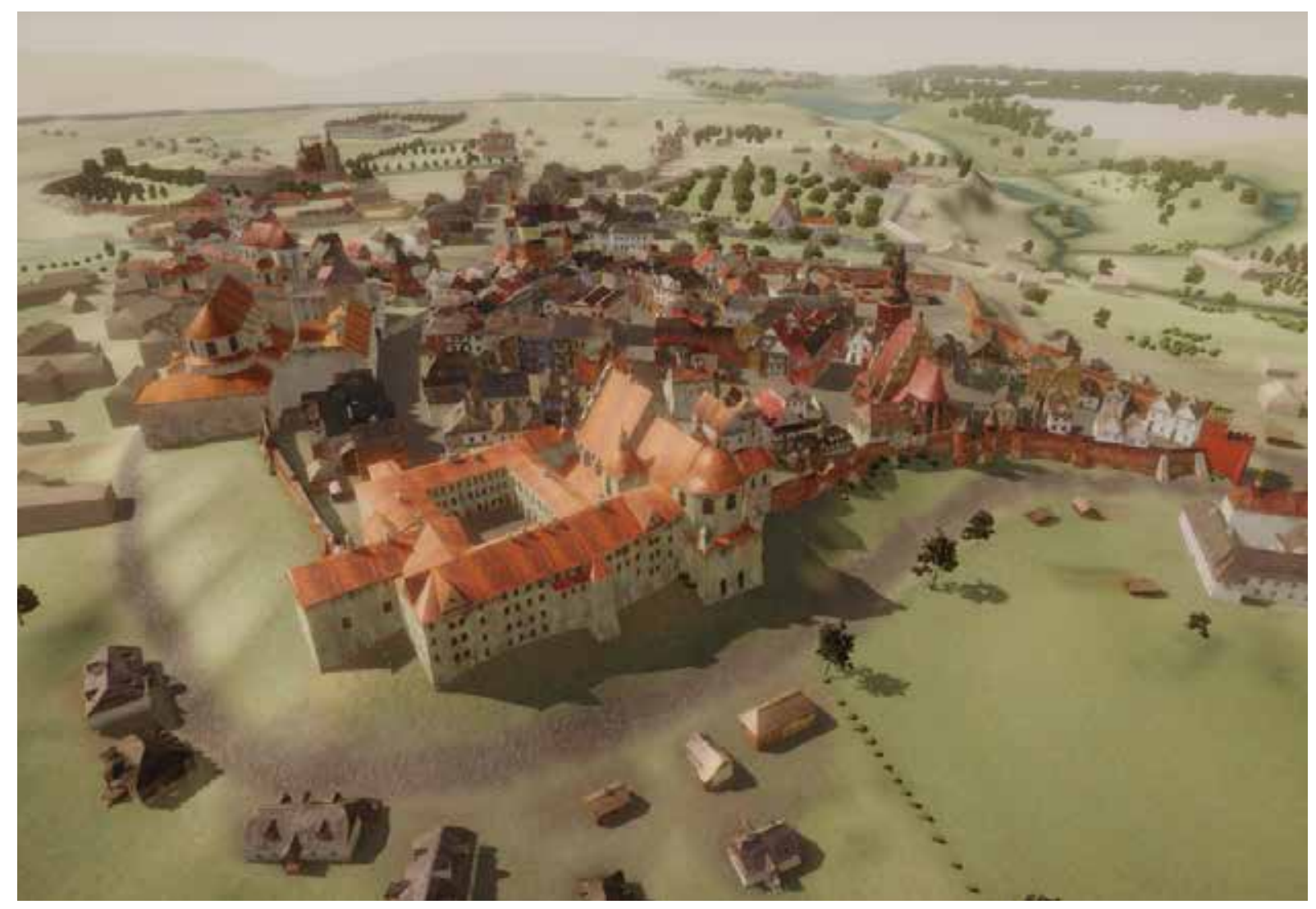

Ilustracja nr 2: Makieta 3D przedstawiająca Lublin w XVIII wieku

Przy okazji lockdownu zostały przypomniane cieszące się dużą popularnością wśród internautów makiety obrazujące rozwój przestrzenny Lublina (http://teatrnn.pl/rozwoj-przestrzenny/makiety-3d-lublina), a także materiały źródłowe w postaci dokumentów archiwalnych przygotowane we współpracy z Archiwum Państwowym w Lublinie w ramach projektu Lublin w dokumencie (https://teatrnn.pl//ublin-w-dokumencie). Opowiadając o Lublinie, ośrodek wykorzystuje również multimedialne mapy (http://teatrnn.pl/miejscal mapy), dzięki którym można poznać topografię nieistniejącej ulicy Szerokiej (http://teatrnn.pl/miejsca/mapa/ulica-szeroka), lokalizację zakładów fotograficznych funkcjonujących w Lublinie do 1939 roku: (http://teatrnn.pl/miejsca/ mapa/zaklady-fotograficzne) czy miejsca, w których rozgrywały się wydarzenia Lubelskiego Lipca '80 (http://teatrnn.pl/miejsca/mapa/lubelski-lipiec-80). 


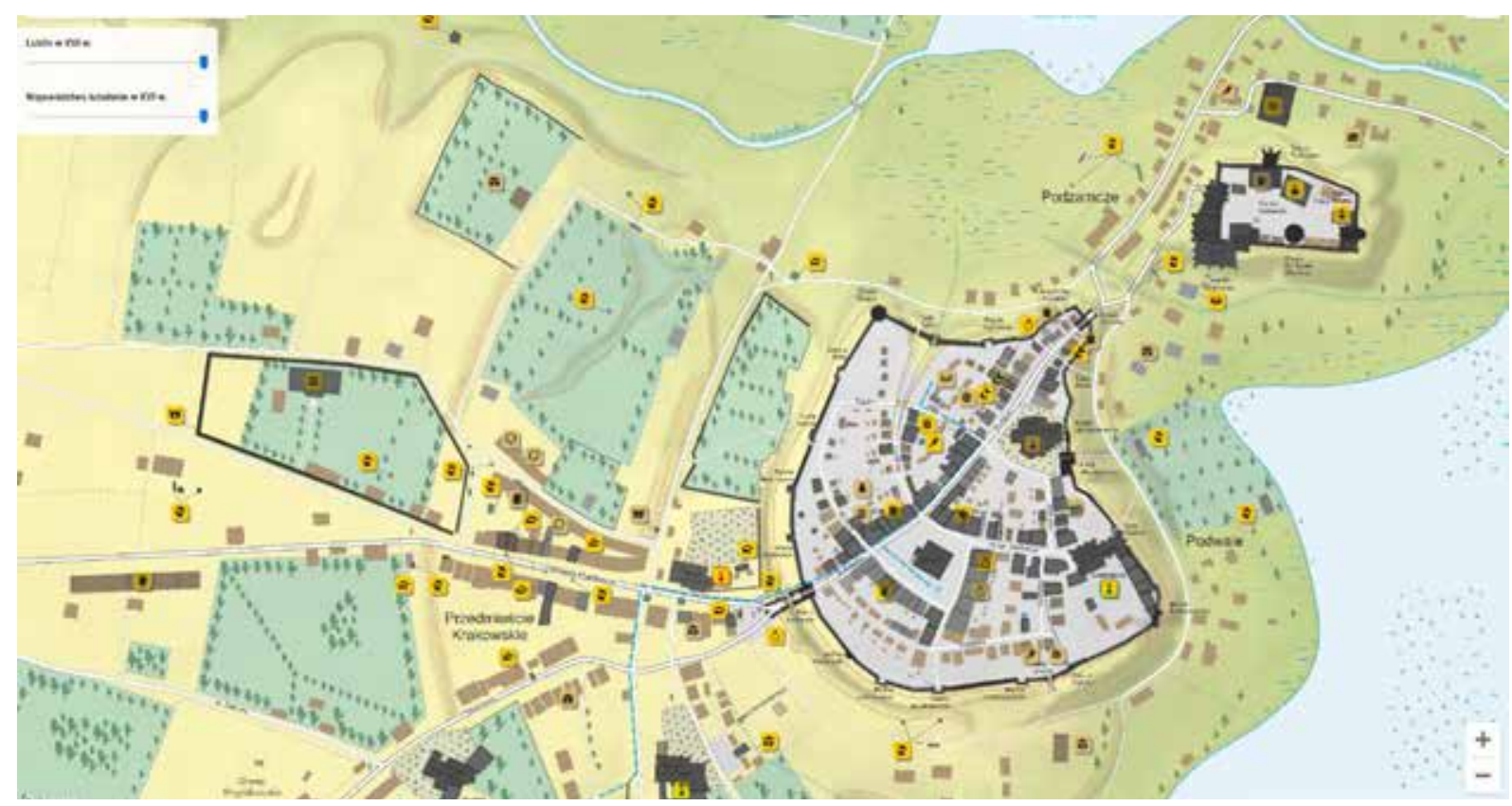

\section{Ilustracja nr 3: Zrzut ekranu z multimedialną mapą przedstawiającą Lublin w okresie Unii Lubelskiej}

Wśród udostępnionych materiałów była też spuścizna jednego z najbardziej znanych polskich fotografów - Edwarda Hartwiga, którego „lubelski” dorobek został udostępniony online w ramach projektu Lublin. Opowieść o mieście (http://teatrnn.pl/opowiesci/lublin-opowiesc-o-miescie). Na stronie tego projektu szczególną wartość mają narracje multimedialne powstałe z wykorzystaniem zdjęć i wspomnień, które - gromadzone przez ośrodek - są wykorzystywane w różnorodnych serwisach tematycznych, np. o lubelskich cegielniach (http://teatrnn.pl/lubelskie-cegielnie), wodociągach (https://teatrnn.pl/lublin-woda), a także o rzemiośle (http://teatrnn.pl/rzemioslo) i pszczelarstwie (http://teatrnn.pl/pszczelarstwo).

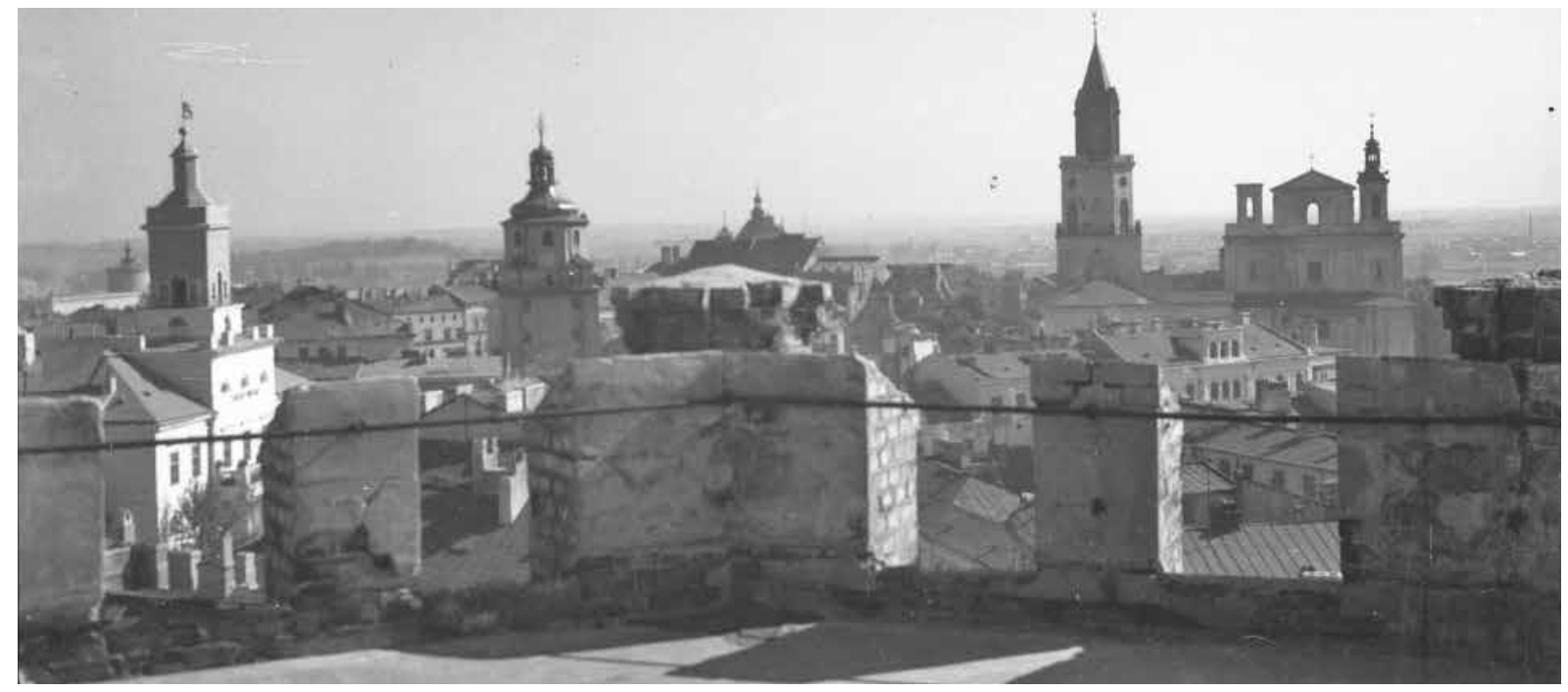

Ilustracja nr 4: Panorama Lublina, lata 40. XX wieku, fot. Edward Hartwig, zbiory Ewy Hartwig-Fijałkowskiej / Pracownia Ikonografii Ośrodka „Brama Grodzka - Teatr NN” 
Szczególnym zainteresowaniem mieszkańców Lublina cieszą się zdjęcia. Są one prezentowane w serwisie „Lublin. Fotografia” dostępnym pod adresem: (https://teatrnn.pl/lublin-fotografia/miejsca-fotografia). W serwisie obejrzeć można m.in. fotografie wykonane przez Józefa Czechowicza, jak również unikalne zdjęcia pochodzące z kolekcji rodzinnych, wykonane przed II wojną światową, oraz fotografie powojenne dokumentujące zmiany w przestrzeni miasta.

Ośrodek od ponad 20 lat rejestruje wspomnienia świadków historii, którzy związani są z Lublinem i Lubelszczyzną. Do marca 2020 roku zostało nagranych 2666 osób i 5600 godzin relacji. Relacje te w formie tematycznych fragmentów udostępniamy na stronie (www.historiamowiona.teatrnn. pl). Zasób można przeszukiwać według nazwisk świadków historii, tematów oraz miejscowości. Zakres czasowy i tematyka nagrywanych opowieści są bardzo szerokie. Aby ułatwić korzystanie ze zbiorów, zostały wyodrębnione kategorie tematyczne związane $\mathrm{z}$ historią Lublina i Lubelszczyzny.

Serwisy Ośrodka „Brama Grodzka - Teatr NN” zawierają także materiały edukacyjne, dostępne na stronie (https://teatrnn.pl/edukacja/materialy-edukacyjne). Osoby zainteresowane historią lubelskich Żydów mogą na przykład zajrzeć na stronę z mini-wykładami poświęconymi tej tematyce, a także zapoznać się z zawartością serwisu dotyczącego wydarzeń z marca 1968 roku w Lublinie. Natomiast w serwisie edukacyjnym „Lublin. Instrukcja obsługi" za pomocą krótkich haseł została przybliżona historia Lublina od czasów najdawniejszych, poprzez okres renesansu, dwudziestolecie międzywojenne, do współczesności. Z kolei na portalu ohistorie.eu znajdują się materiały tekstowe, a także $\mathrm{w}$ formacie wideo, odnoszące się do najnowszej historii Polski. Działająca przy ośrodku Pracownia Instytutu Europy Środkowo-Wschodniej proponuje z kolei stronę (http://teatrnn.pl/ pracownia-iesw/publikacje), z której można pobrać komplet materiałów o historii stosunków polsko-rosyjskich, przygotowanych przez historyków i nauczycieli z Polski i Rosji.

Osoby zainteresowane literaturą, a w szczególności poezją, znajdą wiele informacji w serwisie Strony Poezji (http://stronypoezji.pl), gdzie można zapoznać się z kompendiami wiedzy o twórczości poetów: Stanisława Barańczaka, Ryszarda Krynickiego i Adama Zagajewskiego (http://stronypoezji.pl/monografie). Znajduje się tam również wybór wierszy oraz materiały multimedialne. Na podstronie serwisu Do-po-wiedzenia: (http://stronypoezji.pl/dopowiedzenia) można z kolei wysłuchać rozmów Jacka Podsiadły z poetami.

Fizyczne zamknięcie ośrodka dla publiczności przyczyniło się do przypomnienia archiwalnych wydarzeń, których zapisy są udostępniane w ramach Wideoteki ośrodka; na przykład spotkania i rozmowy oraz seminaria można obejrzeć na kanale YT Bramy Grodzkiej (https://www.youtube.com/channel/ UClR2Vx4yfXNxAp1cOCu4SSQ) oraz na kanale Domu Słów (https://www. youtube.com/user/LublinMiastoPoezji/playlists). W związku z obchodzonym w 2020 roku trzydziestoleciem działalności ośrodka można też zajrzeć 
na strony Kalendarium TNN (http://teatrnn.pl/kalendarium), gdzie udokumentowane są wydarzenia $\mathrm{z}$ historii instytucji, a także na przygotowaną z okazji jubileuszu stronę (https://teatrnn.pl/30lat). Ponadto w Leksykonie Bramy Grodzkiej (https://teatrnn.pl/obgtnn-leksykon) Tomasz Pietrasiewicz - twórca i założyciel - w autorskich tekstach opisuje najważniejsze wydarzenia z historii ośrodka i wyjaśnia istotne dla tej instytucji pojęcia.

\section{Statystyki}

Bogata i zróżnicowana oferta Ośrodka „Brama Grodzka - Teatr NN” trafiła do szerokiego grona odbiorców, o czym najlepiej świadczą statystyki. W okresie od 16 marca do 30 maja 2020 roku strony internetowe (w tym teatrnn.pl, leksykon.teatrnn.pl, biblioteka.teatrnn.pl) odwiedziło 251975 użytkowników. Strony miały 527437 odsłon.

Do najpopularniejszych haseł $\mathrm{w}$ całym Leksykonie Lublin należały: Czerwiec 1989 - przebieg i skutki wyborów 4 czerwca 1989 roku - 8655 odsłon, Upadek muru berlińskiego i zjednoczenie Niemiec (1989) - 8515 odsłon, Wybory do Sejmu Ustawodawczego z 19 stycznia 1947 roku - 6466 odsłon. Do najpopularniejszych haseł dotyczących historii miasta należały: Unia Lubelska (1569) - 4993 odsłony, Etnografia Lubelszczyzny - obrzędy pogrzebowe na Lubelszczyźnie - 2925 odsłon, Freski w kaplicy Trójcy Świętej - 2033 odsłon. Najpopularniejsze filmy z wideoteki to: Miasto reformacji, kultury i wielkiej polityki - wirtualna makieta Lublina z XVI wieku - 2376 wyświetleń, Lublin. Opowieść o mieście: Dzielnica żydowska opowiedziana przez Edwarda Hartwiga - 1556 wyświetleń, Lublin. Opowieść o mieście: Ogród Saski - 861 wyświetleń.

Informacje przekazywane przez ośrodek za pośrednictwem Facebooka także cieszyły się dużym zainteresowaniem. 30 maja 2020 roku profil Bramy Grodzkiej miał 13343 polubienia i 13906 obserwatorów. W okresie od 14 marca do 4 czerwca nastąpił wzrost o 373 osoby; warto dodać, że instytucja nie ma postów sponsorowanych, a cały zasięg jest zasięgiem organicznym.

\section{Perspektywy i możliwości}

Wieloletnie doświadczenie Ośrodka „Brama Grodzka - Teatr NN” w prowadzeniu działań animacyjnych i edukacyjnych z użyciem nowych technologii zaowocowało w warunkach lockdownu - instytucja była w pełni przygotowana na całkowite przeniesienie swojej działalności do sieci. Tworzona od samego początku działalności oferta skierowana jest do szerokiego grona odbiorców: od młodzieży szkolnej, dorosłych, do seniorów; od amatorów i pasjonatów, do badaczy zajmujących się różnymi dziedzinami wiedzy. Praca rozpoczyna się od gromadzenia źródłowej wiedzy o lokalnej historii i dziedzictwie kulturowym. Zbierane i stale uzupełniane - także przy współudziale lokalnej społeczności - materiały są następnie przy użyciu nowych technologii przekształcane w pogłębioną i wielowątkową opowieść 
o przeszłości. W tym celu są one prezentowane za pomocą narracji multimedialnych wykorzystujących montaże obrazu z materiałem audio i video, makiet 3D, spacerów po mieście $\mathrm{z}$ wykorzystaniem wirtualnych map. Dodatkowo media społecznościowe pozwalają na zapoznanie się z tymi materiałami oraz aktywne uczestnictwo odbiorców w tworzeniu opowieści popularyzowanych przez ośrodek. Dobre praktyki opisywanie na stronach ośrodka mogą być bezpośrednio wykorzystywane przez użytkowników, ale instytucji zależy też na ich twórczym przekształcaniu i dostosowaniu do indywidualnych potrzeb odbiorców. Ośrodek „Brama Grodzka - Teatr NN” jest przykładem instytucji kultury, która radzi sobie z edukacyjnym wykorzystaniem współczesnych technologii komunikacyjnych, przez co jest w stanie realizować cele edukacji humanistycznej w nowoczesny sposób ${ }^{5}$.

\section{O Autorach}

Joanna Zętar - historyczka sztuki, dziennika, animatorka kultury, specjalistka w dziedzinie PR. Od 2001 roku pracuje w Ośrodku „Brama Grodzka - Teatr NN”. Redaktor naczelna i content menager portalu www. leksykon.teatrnn.pl działającego $\mathrm{w}$ ramach Laboratorium Teatru NN - Nowe Narracje. Autorka artykułów publikowanych m.in. na łamach kwartalnika „Konteksty”, rocznika „Zagłada Żydów. Studia i materiały”, „Gazety Wyborczej”, na blogu Ośrodka „Brama Grodzka - Teatr NN” oraz w licznych monografiach. Autorka książki Lublin, którego nie ma (2018).

Lukasz Kowalski - politolog, animator kultury, trener, webmaster. Tworzy i wdraża strategie komunikacji w nowych mediach. Interesuje się budowaniem interaktywnych opowieści w internecie. Od 2009 roku koordynator działu Laboratorium Nowe Media w Ośrodku „Brama Grodzka - Teatr NN”. Organizator spotkań i warsztatów dotyczących nowych technologii: THATCampy, TechKluby, RemiksLaby.

\footnotetext{
${ }^{5}$ Więcej na temat działań animacyjnych Ośrodka „Brama Grodzka - Teatr NN” realizowanych z wykorzystaniem nowoczesnych technologii: Bomba R., Brama 2.0. Animacja kultury cyfrowej w działaniach Ośrodka „Brama Grodzka - Teatr NN”, „Konteksty. Polska Sztuka Ludowa. Antropologia kultury - etnografia - sztuka” 2017, nr 3: Misterium Bramy. Antropologia pamięci, s. 141-148; Próchniak P., Brama jako archiwum. Działania archiwistyczne Ośrodka "Brama Grodzka - Teatr NN" w Lublinie, „Kultura i Społeczeństwo”, R. 2019, nr 1: Społeczne w archiwach, s. 113-123.
} 
